\title{
MAIS Sobre A EnTOAÇÃo de SEnTEnÇAS COM ORDEM SV
}

\author{
More on the intonation of SV sentences
}

\author{
Maria Cristina Figueiredo Silva* \\ Izabel Christine Seara*
}

\section{INTRODUÇÃO}

Este trabalho aprofunda o estudo sobre a entoação de sentenças SV "neutras" no português brasileiro (doravante PB), isto é, sentenças que não carregam foco sobre nenhum de seus constituintes, pois são a apresentação de uma situação. Interessa-nos em particular examinar o padrão entoacional desse tipo de sentença em dois contextos discursivos diferentes: um em que o sujeito da sentença faz parte da pressuposição e outro em que ele não é parte da pressuposição.

As línguas humanas, dependendo de certas propriedades sintáticas, podem veicular estas diferentes interpretações do sujeito de maneiras distintas: ou lançam mão de estratégias prosódicas mantendo a mesma ordem linear, ou fazem alguma alteração na ordem das palavras, mantendo a estrutura acentual e entoacional inalteradas.

$O$ interesse deste estudo repousa no fato de o PB, uma língua de sujeito nulo parcial, também ser uma língua de inversão parcial do sujeito, isto é, a inversão é possível apenas em contextos gramaticais restritos. Assim, pode-se perguntar se o falante do PB fará uso de estratégia da inversão nas situações ainda permitidas pela gramática de sua língua (apenas em sentenças com verbos monoargumentais e preferencialmente com DPs indefinidos) ou se o falante usará as estratégias que a prosódia da língua coloca à sua disposição, sem tocar na ordem das palavras na frase, seja qual for o tipo de verbo (doravante V) ou de DP sujeito (doravante DP).

Em pesquisas anteriores, o comportamento do PB já foi parcialmente determinado, mas os experimentos feitos não recriavam um número significativo de situações discursivas, para obter o que se conhece como fala semiespontânea. No presente estudo, o foco de nossa atenção é

\footnotetext{
- UFSC. A primeira autora é bolsista PQII do CNPq, Processo n 312303/2006-8.
} 
exatamente esse tipo de dado. Esperamos mostrar que a literatura que versa sobre o tema está fundamentalmente correta e que o PB já se comporta como uma língua sem inversão do sujeito.

Este trabalho se organiza do seguinte modo: na seção 2, apresentamos brevemente as principais linhas de argumentação encontradas na literatura sobre o assunto; na seção 3 são delineados os testes idealizados para este experimento, juntamente com alguns exemplos de análise dos dados; a seção 4 mostra os resultados obtidos e a última seção contém a discussão desses resultados, apontando direções para pesquisa futura.

\section{A ENTOAÇÃo DAS SENTENÇAS SV E o PB}

As sentenças SV ditas neutras em línguas sem inversão livre do sujeito (como o inglês) exibem dois padrões acentuais distintos segundo o sujeito seja ou não parte da pressuposição (uma observação que remonta a Schmerling (1976) ${ }^{1}$ citada por Ladd (1996) e Cinque (1993), entre outros. Os exemplos clássicos são o anúncio no noticiário da TV norte-americana das mortes de Truman e de Johnson: no primeiro caso, Truman estava doente, sua saúde era assunto diário dos jornais, sendo o sujeito da frase, portanto, parte da pressuposição discursiva. A morte de Johnson, por outro lado, foi um fato inesperado e por isso, neste caso, o sujeito não é parte da pressuposição discursiva - a estrutura acentual é dada abaixo pelo uso de maiúsculas:

(1) a. Truman DIED

b. JOHNSON died

A generalização parece ser que, em línguas como o inglês, quando o sujeito é parte da pressuposição, o acento sentencial recai sobre V; quando, por outro lado, o sujeito não é parte da pressuposição, o acento sentencial aparece sobre o DP. Se, por outro lado, a língua dispõe de inversão livre do sujeito (como o italiano), observa-se alternância na ordem das palavras: a ordem Sujeito-Verbo (SV) é a escolhida quando o sujeito é parte da pressuposição, mas a ordem Verbo-Sujeito (VS) é a escolha quando o sujeito não é parte da pressuposição, como mostra a tradução de (1) para o italiano:
a.
Truman è MORTO
b. È morto JOHNSON

O que esperar de uma língua como o PB, que está perdendo a inversão livre do sujeito? O PB ainda pode lançar mão de VS quando o sujeito não é parte da pressuposição ou só pode usar diferentes padrões acentuais, mesmo em sentenças monoargumentais apresentativas, o contexto discursivo favorecedor por excelência de VS (cf. COSTA et al, 2005)? 
Se o PB está perdendo a construção VS como defende a literatura especializada (cf. BERLINCK, 1988; KATO, 2000, entre outros), o que esperamos é a realização de SV em qualquer contexto discursivo ou gramatical. Pergunta-se então: como são os padrões acentuais de SV no PB atual? A distribuição destes padrões varia segundo as situações discursivas como se observa em inglês? aqui descritos.

São estas questões que pretendemos responder com os experimentos

\section{METODOLOGIA}

É preciso fazer uma observação sobre uma asserção tácita até aqui: a literatura reportada anteriormente (CINQUE, 1993, em particular) trata da distribuição do acento sentencial, o campo da Fonologia Métrica. Por outro lado, aqui faremos experimentos em fonética acústica, que fornecem a curva de pitch dos enunciados, capacitando-nos portanto a fazer a descrição dos eventos tonais como $\mathrm{H}$ (High) ou L (Low) existentes na sentença, o campo da Fonologia Entoacional. Como esses campos se relacionam?

$O$ acento lexical (sobre o qual se constrói o acento sentencial) não possui nenhum correlato físico isolado. Segundo Hayes (1995, p. 6), a variação na altura (isto é, na frequência fundamental), na duração e finalmente na intensidade, nesta ordem, são os correlatos mais confiáveis. O uso efetivo desses correlatos em diferentes construções depende de outras características fonológicas das línguas.

Com respeito ao PB, Moraes (1998, p. 180) afirma que os correlatos acústicos do acento lexical dependem crucialmente da posição da palavra dentro do enunciado. Se ela está dentro do grupo prosódico (uma posição fraca), é uma combinação de intensidade e duração que responde pela proeminência do acento. Por outro lado, se a palavra ocupa a posição final do grupo prosódico (uma posição forte), lugar em que também o acento sentencial se realiza, a frequência fundamental se soma à duração e à intensidade para expressar o acento. A forma exata do contorno de pitch da sentença dependerá largamente da sua modalidade, mas há necessariamente algum movimento de pitch na sílaba acentuada da palavra que ocupa a fronteira final do grupo prosódico.

Portanto, a frequência fundamental pode ser usada como um correlato do acento sempre que o acento lexical coincidir também com o acento de um grupo prosódico, como o do sujeito ou o do predicado (cf. SANDALO, 2004).

Para os presentes propósitos, defenderemos que é possível encontrar evidências para dois padrões acentuais distintos no contorno de pitch dos enunciados dos informantes, dado que as sentenças aqui são sempre do mesmo tipo (declarativas neutras), são formadas por dois grupos prosódicos (o DP sujeito e o verbo) e, porque sentenças monoargumentais com um DP sujeito não complexo são extremamente curtas, apresentam 
poucas possibilidades de variação seja no lugar do acento sentencial, seja no contorno de pitch.

\subsection{TESTES}

Nos testes para averiguar se o PB atual diferencia padrões prosódicos ou ordem das palavras em construções monoargumentais segundo o tipo de estatuto informacional da sentença, utilizamos diferentes tipos de verbos (inacusativos, inergativos) e de DPs (definidos, indefinidos, nomes próprios, animados, inanimados).

O experimento consiste em um conjunto de estórias curtas que tenta criar os contextos discursivos relevantes. Ao final de cada estória, aparece um verbo conjugado e um DP simples que devem ser usados na resposta. Utilizando as ferramentas de apresentação do Power Point, a ordem de aparecimento de cada constituinte é aleatória, bem como a direção que eles tomam para entrar na tela (de baixo para cima, da esquerda para a direita etc.). $O$ informante escolhe a ordem das palavras e a entoação que lhe pareçam mais adequadas ao contexto discursivo apresentado. A princípio, foi elaborado um conjunto de 20 pequenas estórias, das quais 10 deveriam ter o sujeito como parte da pressuposição discursiva, como em (3), e 10 não, como em (4):

(3) A Ana mora num sítio que tem muitas galinhas, mas elas andam sumindo. O pai dela ficou desconfiado que era um lobo que andava por ali e por isso montou guarda de espingarda. Quando a Ana ouviu um tiro, foi correndo no galinheiro perguntar o que tinha acontecido e o pai dela falou:

Itens apresentados aleatoriamente: o lobo, apareceu

(4) Um repórter está em um bar num pequeno vilarejo procurando algum fato interessante para fazer uma matéria para o jornal. Nisso uma mulher vem pela rua gritando:

Itens apresentados aleatoriamente: a garota, sumiu

Várias estórias foram descartadas. Algumas delas retomavam o verbo da estória anterior e, por isso, afinal não foram consideradas expressão de informação nova, como os casos em discussão na literatura. Além disso, apenas 6 elocuções exibem a ordem VS, todas com o verbo aparecer, relativas a 4 estórias diferentes. Essas estórias também foram descartadas do tratamento de SV e os casos de VS foram analisados separadamente. Portanto, para a discussão de SV apenas 10 estórias foram computadas, 5 em que o sujeito não é parte da pressuposição e 5 em que é. Como o teste foi realizado com 4 informantes, todas do sexo feminino, grau universitário, com idade entre 20 e 35 anos, temos ao todo 20 elocuções em que o sujeito não é parte da pressuposição e 20 em que o sujeito é parte da pressuposição discursiva. 


\subsection{As ANÁLISEs EfETUADAS}

Para obter um tratamento uniforme da curva de pitch, processamos as sentenças gravadas usando o programa Momel Intsint for Praat/Windows de Cyril Auran. Desse processamento, obtêm-se, via script do Praat, duas análises: uma com as frases mostrando a curva de contorno de $\mathrm{F}_{0}$ (original) apresentada pelo programa Praat (versão 4.1.21 de Paul Boerma e David Weenink) e a outra sintetizada a partir das medidas acústicas processadas pelo Momel.

O uso do sintetizador Momel-Intsint visa eliminar a subjetividade no julgamento dos eventos tonais, já que, na interpretação das curvas visíveis de $\mathrm{F}_{0}$, nem sempre os contornos são suficientemente claros para permitir uniformidade de análise. Descritores automáticos como o Momel sintetizam medidas acústicas de $\mathrm{F}_{0}$, fazendo uma interpolação da curva, o que facilita a análise de contorno de $\mathrm{F}_{0}$, além de uniformizar todos os dados, tornando a análise mais objetiva. Para assegurar a qualidade da síntese, todavia, é necessário fazer várias escutas da elocução original para avaliar se não houve nenhuma alteração na versão sintetizada.

Abaixo estão três exemplos de telas obtidas pelo nosso experimento. As Figuras mostram a forma de onda e a curva do contorno de pitch sintetizada pelo Momel (linha reta) sobreposta à curva de pitch original (linha curva) da elocução de uma sentença. Na Figura 1, pode-se observar na sentença $A$ Mara viajou que o pico mais proeminente do contorno de pitch se encontra alinhado com o final da sílaba pré-tônica de $\mathrm{V}$.

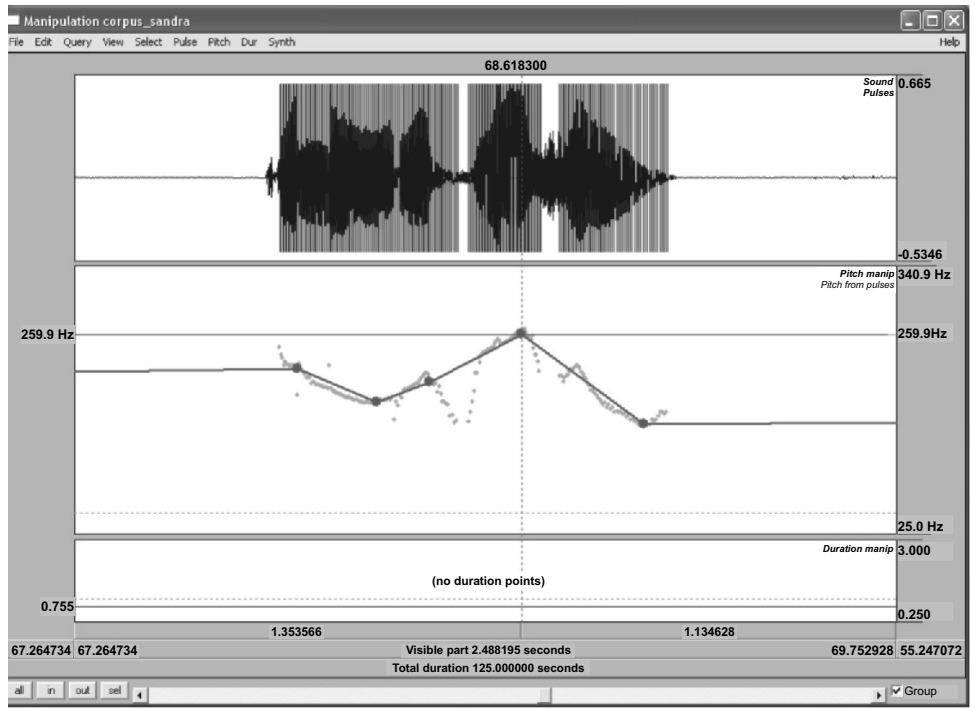

FIGURA 1 - Forma de onda e curva de contorno de pitch sintetizada pelo Momel sobreposta à curva de pitch original da sentença $A$ Mara VIAjou. O pico mais proeminente do contorno de pitch se encontra alinhado com o final da sílaba pré-tônica de V. 
Na Figura 2, em que temos uma elocução da sentença $A$ garota sumiu, o pico mais proeminente do contorno de pitch se encontra alinhado com o início da sílaba pós-tônica do DP:

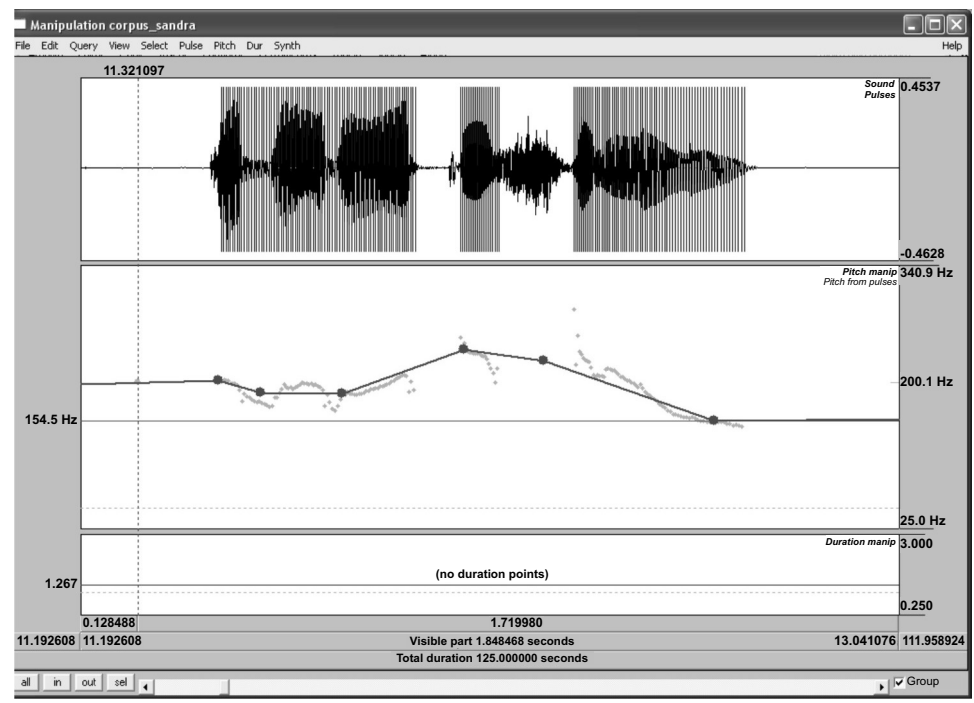

FIGURA 2 - Forma de onda e curva de contorno de pitch sintetizada pelo Momel sobreposta à curva de pitch original da sentença $A$ garoTA sumiu. o pico mais proeminente do contorno de pitch se encontra alinhado com o início da sílaba pós-tônica do DP.

Finalmente, a Figura 3 mostra uma elocução da sentença $O$ lobo uivou, em que há dois picos no contorno de pitch: um alinhado com o final da sílaba tônica do DP e outro, com o final da sílaba tônica do V:

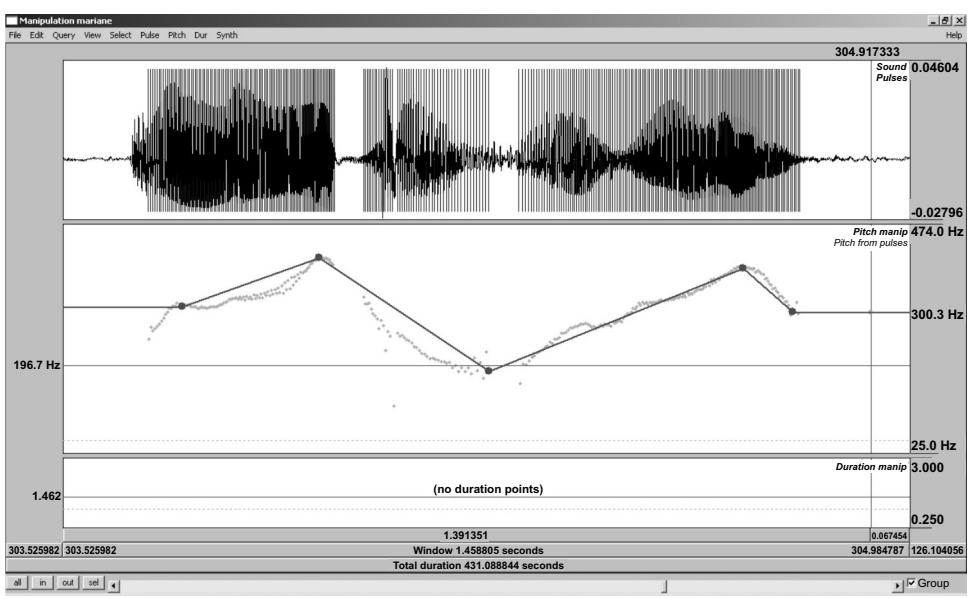

FIGURA 3 - Forma de onda e curva de contorno de pitch sintetizada pelo Momel sobreposta à curva de pitch original da sentença $O$ LObo uiVOU. Os picos mais salientes dos contornos de pitch se encontram alinhados com o final da sílaba tônica do DP e com o final da sílaba tônica de V. 


\section{RESULTADOS}

A Tabela 1 abaixo traz os resultados das narrativas em que 0 sujeito não é parte da pressuposição, caso em que se esperaria a presença de acento sobre o DP:

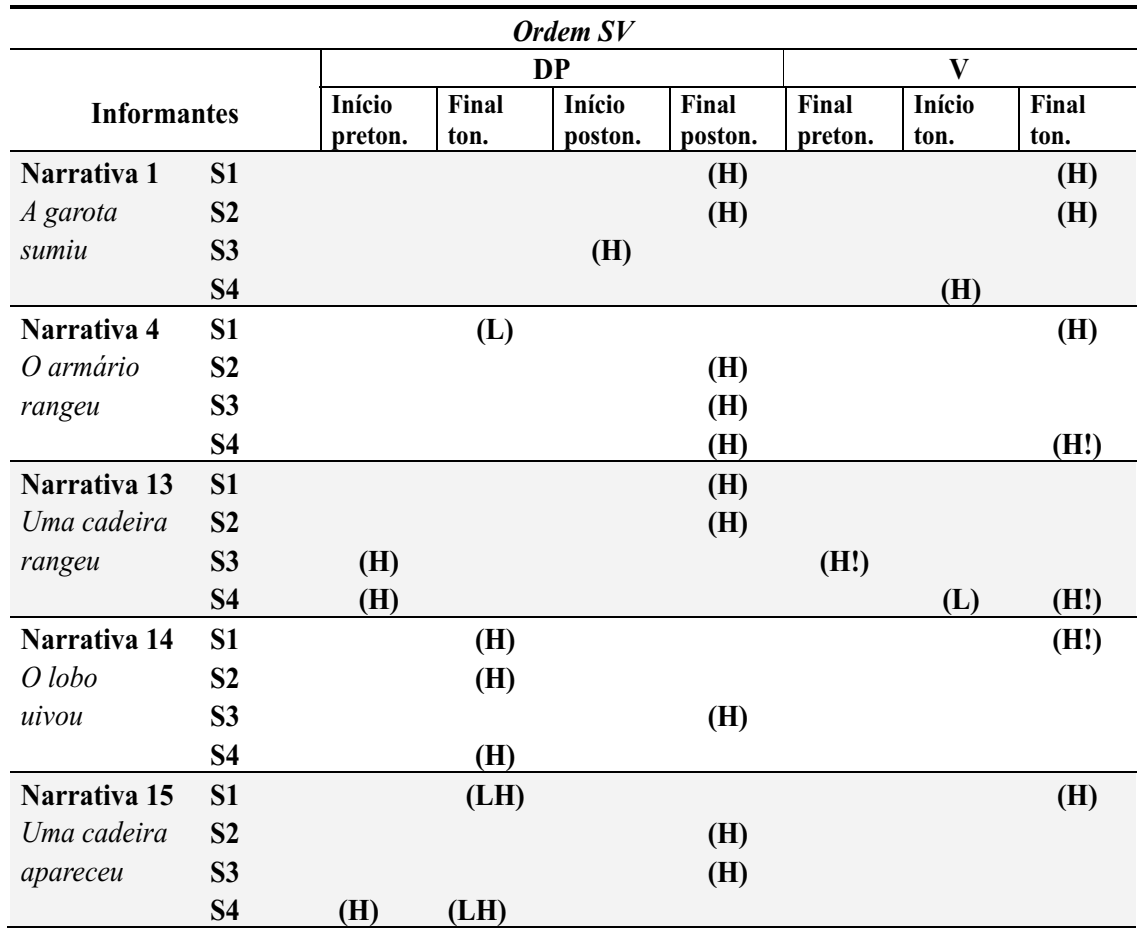

TABELA 1 - EVENTOS TONAIS EM SENTENÇAS SV EM QUE O DP NÃO É PARTE DA PRESSUPOSIÇÃO

É fato que encontramos um evento tonal H sobre o DP em 18 das 20 elocuções ( $90 \%$ dos casos). No entanto, em 7 dessas 18 ocorrências ocorre simultaneamente um evento tonal $\mathrm{H}$ sobre o verbo ( $40 \%$ do total). Em 4 destas 7 ocorrências, o movimento tonal $\mathrm{H}$ observado sobre $\mathrm{V}$ é inferior ao movimento observado sobre o DP, o que nos permitiria interpretar este resultado como favorável, diminuindo para 3 as ocorrências de fato inesperadas de dois movimentos. Portanto, somando essas 3 ocorrências às outras 2 em que há apenas um H sobre V (ou um L sobre DP e H sobre V), ao todo temos 5 ocorrências contrárias ao previsto, o que percentualmente equivale a $25 \%$ das elocuções.

Vejamos agora os resultados da Tabela 2. Como este é o caso em que o DP é parte da pressuposição discursiva, espera-se aqui acento sobre $\mathrm{V}$, traduzido como um evento tonal $\mathrm{H}$ realizado sobre V. Em 15 das 20 
elocuções ( $75 \%$ dos casos) é o que de fato encontramos. Contudo, novamente há coexistência deste evento tonal com um outro, sobre o DP, em 9 ocorrências. Em 6 delas, o evento tonal realizado sobre o DP é L (em 5 elocuções) ou H! (em 1 elocução). Portanto, são 3 (15\% do total) os casos em que há dois eventos tonais $\mathrm{H}$ de igual proeminência sobre o DP e sobre $\mathrm{V}$, um resultado inesperado aqui.

Todavia, realmente surpreendente é a presença, em 5 elocuções, de apenas um evento $\mathrm{H}$ sobre o DP, exatamente o contrário do esperado neste contexto discursivo. A última narrativa produz consistentemente este padrão, realizado por todas as 4 informantes, o que talvez revele a inadequação da narrativa a este contexto discursivo. Na narrativa 19, apresentada em (5), o fato de se mencionar que os móveis quebram com facilidade talvez faça com que, a partir do verbo ranger, seja de algum modo inferível à ação de quebrar. Se este é o caso, toda a informação veiculada pela sentença é dada, o que a distancia das outras sentenças e do experimento em si. Se ainda assim contabilizarmos este resultado, $40 \%$ das elocuções não confirmam nossa hipótese.

\begin{tabular}{|c|c|c|c|c|c|c|c|c|}
\hline \multicolumn{9}{|c|}{ Ordem $S V$} \\
\hline \multirow{2}{*}{\multicolumn{2}{|c|}{ Informantes }} & \multicolumn{4}{|c|}{ DP } & \multicolumn{3}{|c|}{ V } \\
\hline & & \multirow[t]{2}{*}{$\begin{array}{l}\text { Início } \\
\text { ton. }\end{array}$} & \multirow{2}{*}{\begin{tabular}{|l|}
$\begin{array}{l}\text { Final } \\
\text { ton. }\end{array}$ \\
(L) \\
\end{tabular}} & \multirow[t]{2}{*}{$\begin{array}{l}\text { Início } \\
\text { poston }\end{array}$} & \multirow[t]{2}{*}{$\begin{array}{l}\text { Final } \\
\text { poston. }\end{array}$} & \multirow[t]{2}{*}{$\begin{array}{l}\text { Final } \\
\text { preton. }\end{array}$} & \multirow[t]{2}{*}{$\begin{array}{l}\text { Início } \\
\text { ton. }\end{array}$} & \multirow{2}{*}{$\begin{array}{r}\begin{array}{l}\text { Final } \\
\text { ton. }\end{array} \\
\text { (H) }\end{array}$} \\
\hline Narrativa 5 & S1 & & & & & & & \\
\hline A mesa & S2 & & & & & & & (H) \\
\hline \multirow[t]{2}{*}{ sumiu } & S3 & & & & & (H) & & \\
\hline & S4 & & (H) & & & & & (H) \\
\hline Narrativa 7 & S1 & & & & & (H) & & \\
\hline A Mara & S2 & & (L) & & & & & (H) \\
\hline \multirow[t]{2}{*}{ viajou } & S3 & & (L) & & & (H) & & \\
\hline & S4 & & (L) & & & & & (H) \\
\hline Narrativa 9 & S1 & & & & (H) & & & (H) \\
\hline A mesa & S2 & & & & & (H) & & \\
\hline \multirow[t]{2}{*}{ rangeu } & S3 & & & (H!) & & (H) & & \\
\hline & S4 & & (L) & & & & & (H) \\
\hline Narrativa 17 & S1 & & & & & & & (H) \\
\hline A garota & S2 & & & & (H) & & & (H) \\
\hline \multirow[t]{2}{*}{ Dormiu } & S3 & & & & (H) & & & \\
\hline & S4 & & & & & & & (H) \\
\hline Narrativa 19 & S1 & & (H) & & & & & \\
\hline A cadeira & S2 & & & & (H) & & & \\
\hline \multirow[t]{2}{*}{ rangeu } & S3 & & & & (H) & & & \\
\hline & S4 & & (H) & & & & & \\
\hline
\end{tabular}

TABELA 2 - EVENTOS TONAIS EM SENTENÇAS SV EM QUE O DP É PARTE DA PRESSUPOSIÇÃO 
(5) Narrativa 19: Lá no trabalho tem uns móveis super velhos e volta e meia quebra alguma coisa quando a gente está usando. Outro dia eu vi o Pedro levantando rapidinho da cadeira em que ele estava sentado e, quando eu perguntei pra ele por que ele levantou tão rápido, ele me disse: $A$ cadeira rangeu.

A Fig. 4 sumariza os resultados exibidos pelas Tabelas 1 e 2 .

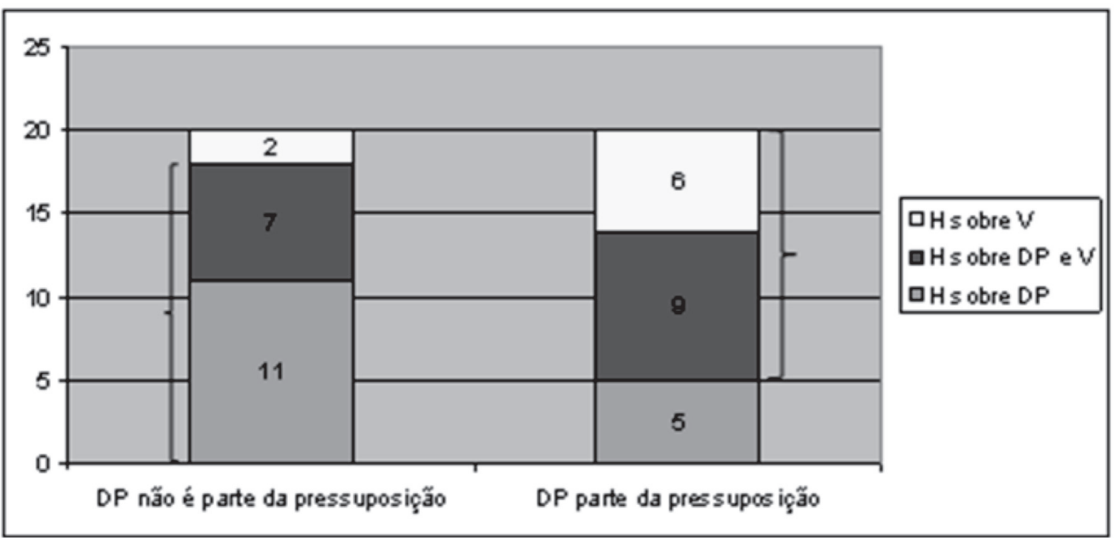

FIGURA 4 - Número de ocorrências de um evento tonal H em sentenças SV em que DP não é parte da pressuposição discursiva e em que DP é parte da pressuposição discursiva.

Lembremos que este experimento permitia ao informante a escolha da ordem SV ou VS. A preferência maciça foi pela ordem SV. Há, no entanto, 6 ocorrências da ordem VS, documentadas nas tabelas 3 e 4 a seguir.

\begin{tabular}{|l|l|l|l|l|l|l|l|l|}
\hline Ordem VS & & & & & & & & \\
\hline & Informantes & V & & & & DP & & \\
\hline & & $\begin{array}{l}\text { Final } \\
\text { pré-tôn }\end{array}$ & $\begin{array}{l}\text { Início } \\
\text { Tônica }\end{array}$ & $\begin{array}{l}\text { Fin. V } \\
\text { Tônica. }\end{array}$ & $\begin{array}{l}\text { Início } \\
\text { Tônica }\end{array}$ & $\begin{array}{l}\text { Final } \\
\text { Tônica }\end{array}$ & $\begin{array}{l}\text { Início } \\
\text { pós-tôn. }\end{array}$ & $\begin{array}{l}\text { Final } \\
\text { pós-tôn. }\end{array}$ \\
\hline Narrativa & S1 & & & & & & & \\
\hline Apareceu & S2 & & & H & & & & \\
\hline uma cadeira & $\mathbf{S 3}$ & & & LH & & & & \\
\hline & S4 & & & & & & & \\
\hline Narrativa & S1 & & & & & & & \\
\hline Apareceu & S2 & & & & & & & \\
\hline um lobo & $\mathbf{S 3}$ & & & & H & & & \\
\hline & S4 & & & & & & & \\
\hline
\end{tabular}

TABELA 3 - EVENTOS TONAIS EM SENTENÇAS VS EM QUE O DP NÃO É PARTE DA PRESSUPOSIÇÃO (ESPERA-SE ACENTO NO DP) 


\begin{tabular}{|c|c|c|c|c|c|c|c|c|}
\hline \multicolumn{9}{|l|}{ Ordem VS } \\
\hline & Informantes & $\mathrm{V}$ & & & & DP & & \\
\hline & & $\begin{array}{l}\text { Final } \\
\text { pré-tôn }\end{array}$ & $\begin{array}{l}\text { Início } \\
\text { Tônica }\end{array}$ & $\begin{array}{l}\text { Fin. V } \\
\text { Tônica. }\end{array}$ & $\begin{array}{l}\text { Início } \\
\text { Tônica }\end{array}$ & $\begin{array}{l}\text { Final } \\
\text { Tônica }\end{array}$ & \begin{tabular}{|l|} 
Início \\
pós-tôn.
\end{tabular} & $\begin{array}{l}\text { Final } \\
\text { pós-tôn. }\end{array}$ \\
\hline F1 & S1 & & & $\mathrm{H}$ & & & & \\
\hline Apareceu a & S2 & & & H & & & & \\
\hline \multirow[t]{2}{*}{ garota } & S3 & & & & & & & \\
\hline & S4 & & & & & & & \\
\hline F2 & S1 & & & & & & & \\
\hline Apareceu o & S2 & & & & & & & \\
\hline \multirow[t]{2}{*}{ lobo } & S3 & & & $\mathbf{H}$ & & & & \\
\hline & S4 & & & & & & & \\
\hline
\end{tabular}

TABELA 4 - EVENTOS TONAIS EM SENTENÇAS VS EM QUE O DP É PARTE DA PRESSUPOSIÇÃO (ESPERA-SE ACENTO EM V)

Essas duas tabelas revelam um fato curioso: apenas com o verbo aparecer a ordem VS é escolhida pelos informantes, e isto independe completamente da situação discursiva, pois VS aparece tanto quando o DP sujeito não é parte da pressuposição (Tabela 3) quanto quando ele é parte da pressuposição (Tabela 4).

O caso apresentado na Tabela 4 é particularmente interessante porque, neste contexto específico, mesmo línguas que lançam mão da ordem VS em outros contextos discursivos aqui utilizam SV e não VS. Contudo, é de se observar que os informantes de qualquer modo realizaram o evento tonal mais importante sobre $\mathrm{V}$, não sobre o DP invertido, o que parece mostrar que, mesmo que os falantes de PB não conheçam mais a gramática de VS, eles conhecem bem a prosódia da língua.

Talvez a surpresa esteja mesmo na Tabela 3: em 2 dos 3 casos em que ocorre VS quando o DP não é parte da pressuposição, os informantes exibem o pico de $f o$ sobre $\mathrm{V}$, um fato inesperado dado o contexto discursivo no qual a frase se insere. Essas 2 elocuções são as mais imprevisíveis de todo o experimento: os informantes invertem o DP para colocá-lo na posição de acento, mas colocam o acento em outro lugar.

\section{CONCLUSÕES}

Certos resultados mostrados na seção anterior são bastante inesperados. Ouvindo atentamente as elocuções obtidas neste experimento de produção, observamos que, em alguns casos, as respostas dos informantes não parecem adequadas às estórias relacionadas a elas, isto é, as respostas não expressam exatamente o estatuto informacional do DP, se parte ou não da pressuposição discursiva. Assim, parece necessário averiguar se o faltante está consciente das respostas que está fornecendo a uma dada situação elicitadora. Por esta razão, indicamos como o próximo passo para a nossa pesquisa um experimento perceptual, em que os informantes, escutando a estória e duas alternativas de respostas a elas, apontem a que lhes soa a mais adequada. Em particular, parece-nos importante entender o que significa exatamente a co-ocorrência de eventos tonais na mesma elocução e como a presença de dois eventos tonais é interpretada pelo ouvinte. 


\title{
RESUMO
}

Este trabalho visa aprofundar o estudo da entoação de sentenças SV neutras em português brasileiro em dois contextos discursivos diferentes: um em que o sujeito é parte da pressuposição discursiva e outro em que o sujeito não é parte do pano de fundo discursivo.

Palavras-chave: entoação; português brasileiro; interface sintaxe-fonologia.

\begin{abstract}
This paper aims at shedding some light on the study of neutral SV intonation in Brazilian Portuguese in two different discourse contexts: one in which the subject is part of the discourse presupposition, and another one in which the subject is not part of the discourse background.

Keywords: intonation; Brazilian Portuguese; syntaxphonology interface.
\end{abstract}

\section{REFERÊNCIAS}

BERLINCK, Rosane de Andrade. A ordem V SN no português brasileiro: sincronia e diacronia. Dissertação (Mestrado) - Unicamp - IEL, Campinas, 1988.

CINQUE, Giulielmo. A Null Theory of Phrase and Compound Stress. Linguistic Inquiry, Massachussets, v. 24, p. 239-297, 1993.

COSTA, João et al. On VS order and null subjects in European and Brazilian Portuguese. Ms. Universidade Nova de Lisboa / Universidade do Porto / Universidade Federal de Santa Catarina, 2005.

HAYES, Bruce. Metrical Stress Theory. Chicago: The University of Chicago Press, 1995.

KATO, Mary. A restrição da monoargumentalidade da ordem vS no português do Brasil. Fórum Lingüístico, Florianópolis, v. 2, p. 97-127, 2000.

LADD, Robert. Intonational Phonology. Cambridge: Cambridge University Press, 1996.

MORAES, João. Intonation in Brazilian Portuguese. In: HIRST, D.; DI CRISTO, A. (Orgs.). Intonation System. A Survey of Twenty Languages. Cambridge: Cambridge University Press, 1998. p. 179-193.

SÂNDALO, Filomena. Fonologia Prosódica e Teoria da Otimalidade: reflexões sobre a interface sintaxe e fonologia na formação de sintagmas fonológicos, 2004. Disponível em: <http://www.ime.usp.br/ tycho/participants/sandalo>. Acesso em 02/02/2008.

Submetido em: 10/03/2008.

Aceito em: 31/03/2009. 